\title{
Crystal Structure and Liquid Crystalline State of Cholesteryl Butylcarbonate
}

\author{
Young Ja Park \\ Deparment of Chemistry, Sookmumg Women's Cniversity, Seoul 1+0-712. Korea. E-mail: viparkiàsoohmymg ac.kr \\ Received January 1, 2007
}

Key Words : Cholesteryl butylcarbonate, Polymorphs. Liquid crystal

The crystal crystal structures of a series of esters and carbonates of cholesterol was exanined, in order to obtain structural information relevant to their liquid crystalline phases and the possible modes of association of the cholesterol derivatives. as well as of other substances in biological systems. ${ }^{1}$ An examination of the unit-cell parameters of the cholesterol derivatives suggests that the majority of them might have one of the four common cry stal packing arrangements. ${ }^{2}$ - However, the crystal data of the cholesteryl butylcarbonate obtained in this study indicate that this carbonate belongs to none of these four crystal structure types.

Cholesteryl butylcarbonate crystallized into two polymorphic forms both of which exhibited liquid crystalline states. By carrying out the crystal structure determination of cholesteryl butylcarbonate. we have provided information on which to base extrapolations concerning the structures of the liquid phases of cholesteryl buty lcarbonate.

\section{Experimental Section}

The title compound was obtained from Tokyo Kasei Kogyo Co. Ltd. The compound crystallized into two polymorphic forms. viz. platelike and blocklike from an acetone solution at room temperature, as shown in Figure 1. The platelike crystals can be obtained from a DMF-chloroform mixed solution and a hexane solution.

The x-ray diffraction data of both crystals mounted on a loop were measured at $100 \mathrm{~K}$ with synchrotron radiation ( $\hat{\lambda}$ $=0.7000 \AA$ ) on a HA MXW ADSC Quantun-210 detector with a silicon double crystal monochromator at the Pohang Accelerator Laboratory: Korea. The raw data were processed and scaled using the program HKL2000 ${ }^{\circ}$ The structure of platelike form was solved by direct methods and the refinements were carried out with full-matrix least-squares on $\mathrm{F}^{2}$

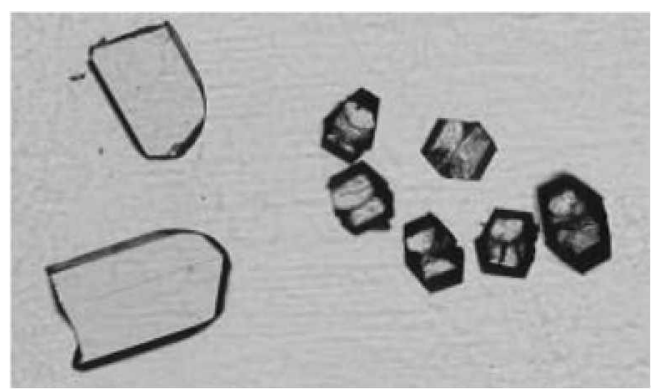

Figure 1. Photograph of single crystals of cholesteryl butylcarbonate, which exhibits a plate and block morphology
Table 1. Summary of crystal data of cholesteryl butylcarbonate

\begin{tabular}{ll}
\hline & Platelike crystal \\
Crystal data & \\
$C_{32} \mathrm{H}_{44} O_{3}$ & $D_{x}=1.100(\mathrm{calc}) \mathrm{g} \mathrm{cm}^{-3}$ \\
$\mathrm{H} m=486.78$ & Synchrotron radiation \\
Monoclinic, $\mathrm{P}_{1}$ & $(\lambda=0.7000 \AA)$ \\
$a=13.983(6) \AA$ & \\
$b=7.5350(15) \AA$ & $\mu=0.068 \mathrm{~mm}^{-1}$ \\
$c=28.526(6) \AA$ & $\mathrm{T}=100(2) \mathrm{K}$ \\
$\beta=101.95(3)^{\circ}$ & Plate, Colorless \\
$V=2940.4(10) \AA^{2}$ & $0.40 \times 0.27 \times 0.15 \mathrm{~mm}$ \\
$Z=4$ &
\end{tabular}

Data collection

ADSC Quantum 210 CCD

$\begin{array}{ll}\text { Diffractometer } & \theta_{\max }=30.4^{\circ} \\ \omega \text { scan type } & h=-20 \rightarrow 20 \\ \text { Absorption conection: none } & k=-10 \rightarrow 0 \\ 16617 \text { measured reflections } & l=-40 \rightarrow 41 \\ 9337 \text { reflections with } \mathrm{I}>2 \sigma(\mathrm{I}) & \mathrm{R}_{\text {ut }}=0.035\end{array}$

Refinement

Refinement on $F^{2}$

$\mathrm{R}\left[F^{2}>2 \sigma\left(F^{2}\right)\right]=0.0393$

wR $\left(F^{2}\right)=0.1063$

$S=1.050$

9337 retlections

631 parameters

$$
\begin{aligned}
& w=1 /\left[\mathrm{s}^{2}\left(F_{0}{ }^{2}\right)+(0.0731 P)^{2}+\right. \\
& 0.226 P] \\
& \text { where } P=\left(F_{0}^{2}+F_{0}^{2}\right) / 3 \\
& (\Delta \sigma)_{\text {tueal }}=0.000 \\
& \Delta \rho_{\max }=0.266 \mathrm{eA}^{-3} \\
& \Delta \rho_{\min }=-0.272 \mathrm{eA}^{-3}
\end{aligned}
$$

\section{Crystal data}

$D_{\mathrm{r}}=1.102\left(\mathrm{calc}\right.$ ) $\mathrm{g} \mathrm{cm}^{-3}$

Blocklike crystal

Monoclinic, $\mathrm{P}_{1}$

$a=8.878(2) \AA$

$b=23.796(5) A$

$c=27.815(6) \AA$

$\beta=95.45(3)^{\circ}$

$V=58660(2) \AA^{3}$

$Z=8$

Synchrotron rádiation

$\left(\hat{A}_{2}=0.7000 \AA\right)$

$\mu l=0.068 \mathrm{~mm}^{-1}$

$\mathrm{T}=100(2) \mathrm{K}$

Block, Colorless

$0.50 \times 0.35 \times 0.15 \mathrm{~mm}$

Data collection

$\theta_{\max }=22.82^{\circ}$

$h=0 \rightarrow 9$

Absorption corection: none

$k=-25 \rightarrow 25$

12911 measured retlections

$l=-29 \rightarrow 29$

9750 reflections with $\mathrm{I}>2 \alpha(\mathrm{I})$
$\mathrm{R}_{\text {utt }}=0.047$ 


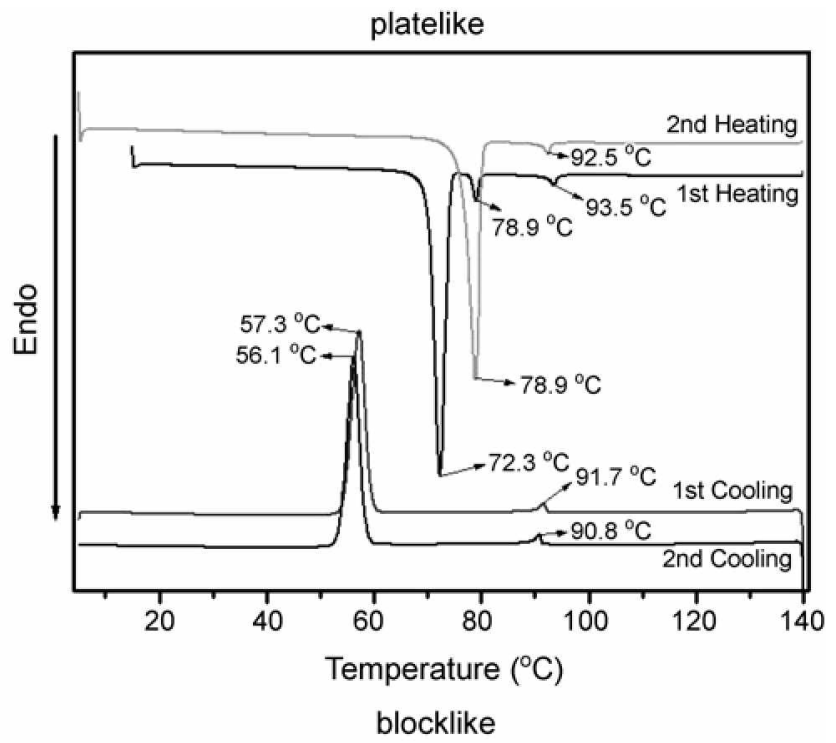

(a) platelike crystal

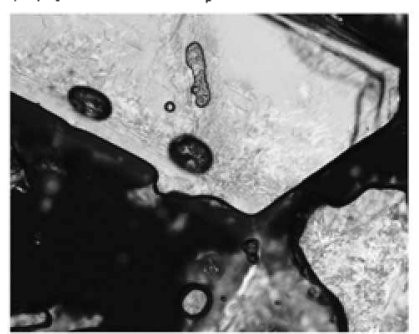

at $72.1^{\circ} \mathrm{C}$ on Heating $(100 \mathrm{x})$

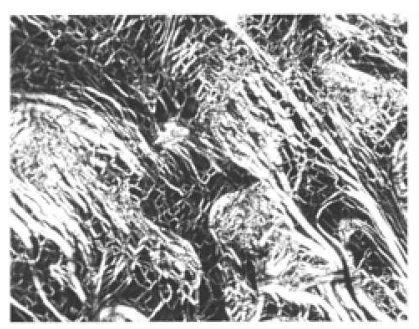

at $81.1^{\circ} \mathrm{C}$ on heating $(100 x)$

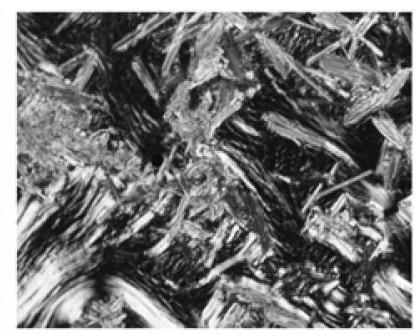

at $78.7^{\circ} \mathrm{C}$ on Heating $(100 x)$

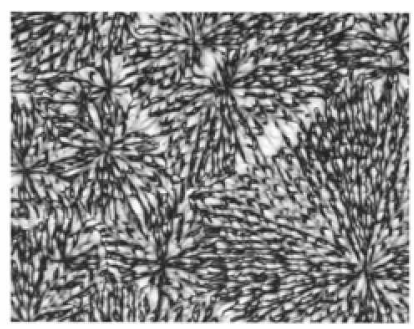

at $74.1^{\circ} \mathrm{C}$ on cooling $(400 \mathrm{x})$

(b) blocklike crysial

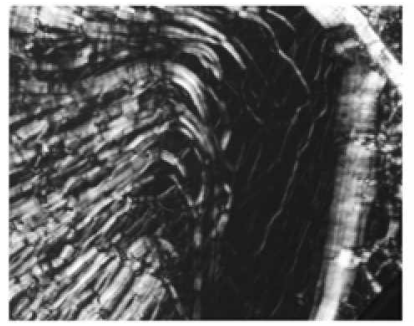

at $84.9^{\circ} \mathrm{C}$ on heating $(400 \mathrm{x})$

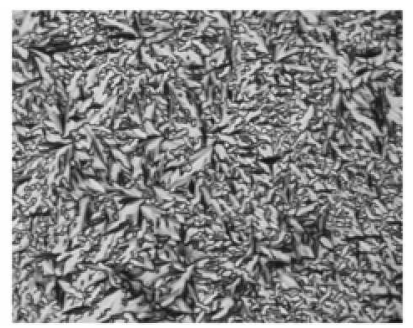

at $77.6^{\circ} \mathrm{C}$ on cooling $(400 \mathrm{x})$

Figure 3. Optical polarized micrographs of cholestery l buty lcarbonate: (a) platelike crystal (b) blocklike crystal

two molecules are shown in Figure 4. The bond lengths and angles agree well with those of other cholesterol derivatives. ${ }^{8.11}$ The conformations of the tetracyclic ring systems in molecules $\mathrm{A}$ and $\mathrm{B}$ are quite similar. The selected torsion angles in Table 2 are for the cholesteryl tails and carbonate chains. where the major differences in conformation occur. The C17-C.26 tail of the two molecules is almost fully extended. as in most cholesterol derivatives. The major difference in the overall shape of the molecules can be attributed to the twist of the ester chains about the $\mathrm{C} 3-\mathrm{O} 3$ bond. The torsion angle of C.2-C3-O3-C.28 are 151.27(12) and 80.76(16) in molecule A and B. respectively. The carbonate chains of both molecules are fully extended.

In the crystal structure (Figure 5) of cholesteryl butylcarbonate. the molecules are arranged in bilayers. in each of which there is a parallel arrangenent of the two crystallographically independent molecules. A and B. and an antiparallel arrangement of molecules related by a screw axis. The molecules in bilayer are partly interdigitated and tilted with respect to the layer planes. The best least-squares planes through the atons of the cholesterol rings in molecules A and $\mathrm{B}$ are almost parallel with an interplanar angle of $4.34(3)^{\circ}$. At the center of the bilayers. there is a close packing involving the cholesteryl-cholesteryl. cholesteryl-C17 tails and
Cholesteryl butylcarbonate contains two molecules (A and B) in an asymmetric unit. The molecular structures of these 


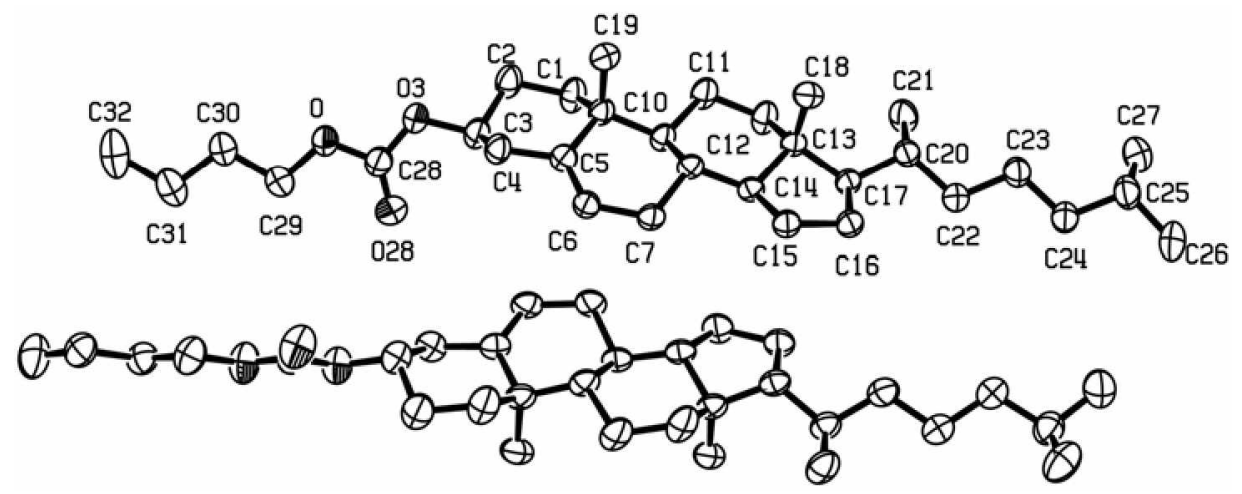

Figure 4. Best view of the asymunetne unit, with the atomic numberng shown only for molecule $A$. Displacement ellipsolds are drawn at the $80 \%$ probablity level and the $\mathrm{H}$ atoms have been omitted for the sake of clarity.

Table 2. Comparison of selected torsion angles $\left({ }^{\circ}\right)$ The e.s.d.'s are in parentheses

\begin{tabular}{lcc}
\hline & Molecule A & Molecule B \\
Butylcarbonate chain & & \\
C1-C2-C3-O3 & $179.61(11)$ & $171.89(11)$ \\
C2-C3-O3-C28 & $151.27(12)$ & $80.76(16)$ \\
C4-C3-O3-C28 & $-89.16(14)$ & $-158.82(13)$ \\
C3-O3-C28-O28 & $-3.6(2)$ & $-4.3(2)$ \\
C3-O3-C28-O & $176.45(11)$ & $175.86(13)$ \\
O28-C28-O-C29 & $-4.7(2)$ & $0.2(3)$ \\
O3-C28-O-C29 & $175.19(12)$ & $-179.93(13)$ \\
C28-O-C29-C30 & $-173.02(12)$ & $175.13(13)$ \\
O-C29-C30-C31 & $-177.15(12)$ & $-178.74(13)$ \\
C29-C30-C31-C32 & $-178.11(14)$ & $-177.10(13)$ \\
& & \\
C17 side tail & & \\
C13-C17-C20-C21 & $-61.03(14)$ & $-59.41(16)$ \\
C13-C17-C20-C22 & $175.71(10)$ & $176.69(11)$ \\
C16-C17-C20-C21 & $177.54(11)$ & $179.76(12)$ \\
C16-C17-C20-C22 & $54.28(14)$ & $55.86(14)$ \\
C17-C20-C22-C23 & $-170.24(11)$ & $-177.54(12)$ \\
C21-C20-C22-C23 & $65.54(14)$ & $57.56(16)$ \\
$\mathrm{C} 20-C 22-C 23-C 24$ & $176.65(11)$ & $172.80(12)$ \\
C22-C23-C24-C25 & $-175.88(12)$ & $-179.50(12)$ \\
C23-C24-C25-C26 & $173.74(14)$ & $176.39(14)$ \\
C23-C24-C25-C27 & $-62.81(16)$ & $-60.41(17)$ \\
\hline
\end{tabular}

cholesteryl-butylcarbonate chains. Within each layer. there are three different packing regions. Regions of packed cholesteryl ring systems alternate with regions of packed C17 tails. and with butylcarbonate packing regions (See Figure 5).

As expected. the crystal structure does not belong to any of the four main crystal structure types. but is similar to that of cholesteryl myristate. Both of these crystal structures form bilayers. The main crystal structural differences are the packing mode involving the cholesteryl ring sy'stems and the longer myristate chain packing in the cholesteryl myristate.

As shown in Figure 3, the platelike cry'stals melt to give an isotropic liquid (at $93.5^{\circ} \mathrm{C}$ ) with two intermediate liquid cry stalline phases (at 72.3 and $78.9^{\circ} \mathrm{C}$ ). The blocklike cry stals (a)
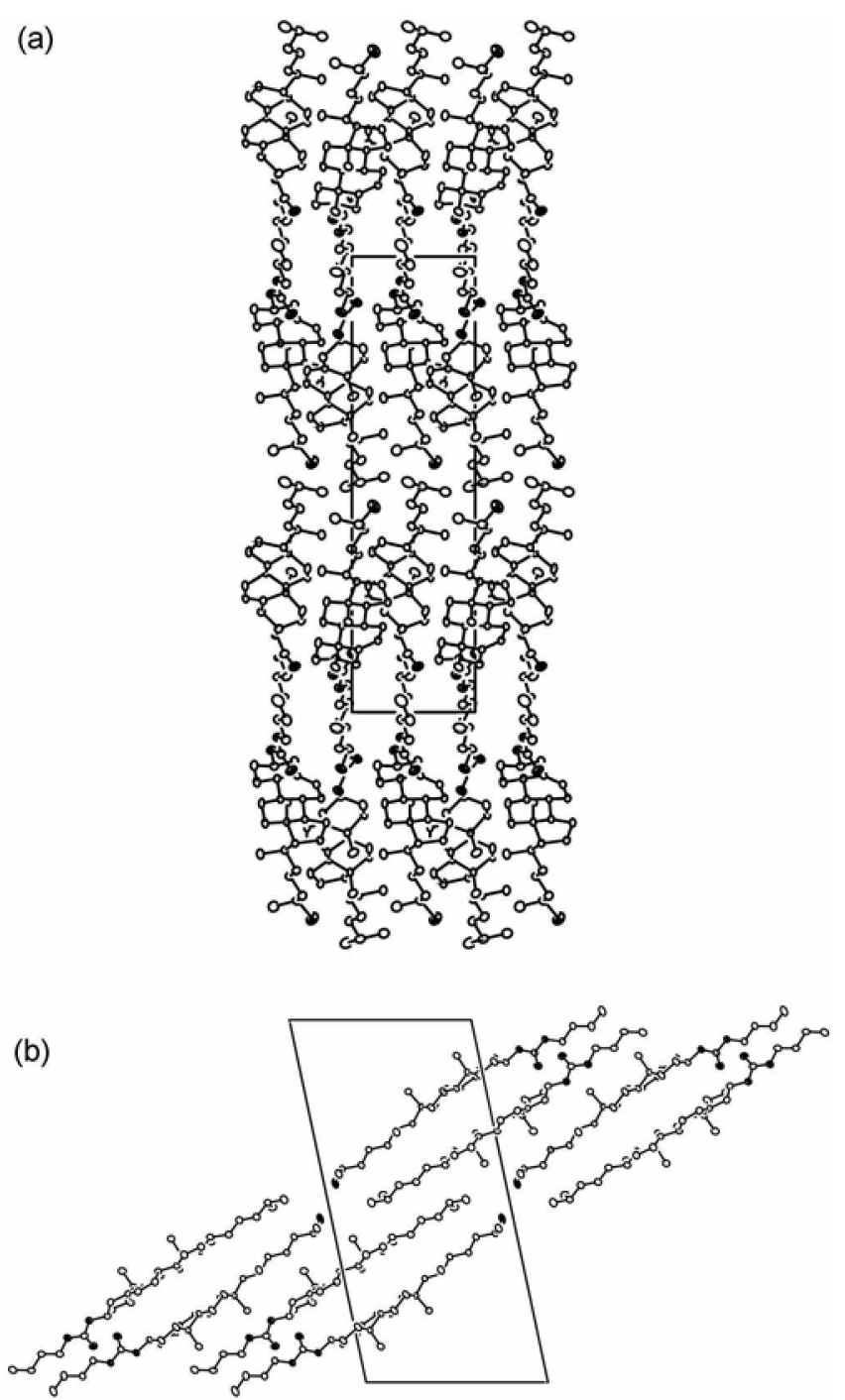

Figure 5. (a) The rystal packung viewed down the $a$ axis. The $b$ axis is horizontal. (b) Part of the crystal structure showing the parallel and antiparallel molecular arrangement viewed down the $b$ axis. Octant shading indicates oxygen atoms and C26 atoms of molecule A

melt at 92.8 with an intermediate cholesteric phase (at 81.1 ${ }^{\circ} \mathrm{C}$ ). The following themal transition path is suggested: 
$72^{\circ} \mathrm{C} \quad 78^{\circ} \mathrm{C} \quad 93^{\circ} \mathrm{C}$
Platelike crystal $\rightarrow$ mesophase $\rightarrow$ cholesteric $\leftrightarrow$ isotropic liquid $53{ }^{\circ} \mathrm{C} \downarrow \uparrow 78^{\circ} \mathrm{C}$

blocklike crystal

The cholesteric liquid crystalline phases are confirmed by representative oily streak textures exhibited on heating at 81 ${ }^{\circ} \mathrm{C}$ and on cooling at $74^{\circ} \mathrm{C}$. The first mesophase observed in the platelike crystal can be considered as a mixture of crystal and cholesteric liquid crystal or smectic phases, but more data are needed to confinn this inference. Small angle $x$-ray diffraction data may be necessary to confirm the smectic phase. Cholesteryl myristate also shows smectic and cholesteric phases.

In the smectic mesophase, the molecules are arranged side by side in a series of stratified layers. The molecules in the layers may be arranged in a regular or randon side by side spacing arrangement. The long axes of the molecules are parallel to one another. and each layer can be one or more molecules thick. The cholesteric mesophase resembles the smectic mesophase in that the molecules are arranged in layers. ${ }^{12}$ The crystal structures of cholesteryl butylcarbonate as well as that of cholesteryl myristate exhibit the parallel arrangement of the molecules within bilayers. which may be retained in corresponding smectic or cholesteric mesophases. The liquid crystalline behavior of cholesteryl butylcarbonate seems to be consistent with the nature of the layer packing arrangement.

Acknowledgements. This research was supported by Research Grants from Sookmyung Women's University, 2006. The x-ray diffraction experiments using synchrotron radiation were performed at the Pohang Accelerator Laboratory (beam line 4A MXW), supported by MOST and
Pohang University of Science and Teclunology. We wish to thank Professor Jung-Il Jin. Korea University for providing the thermal measurements and polarized optical microscope. and Professor M. S. Lah. Hanyang University for helping us with the collection of the x-ray diffraction data.

Supporting Information Materials. The cry stallographic data for cholesteryl butylcarbonate have been deposited at the Cambridge Crystallographic Data Centre and allocated the deposition number CCDC 632244. That data can be obtained free of charge via http//www.ccde.can .ac.uk/perl/ catreq.cgi

\section{References}

1. Abrahamsson. S.: Dahlen. B ; Lofgren, H.: Pascher, I ; Sundell, S. In Stricture of Biological Mentbratex: Abrahamsson. S.: Pascher. I.. Eds.: Plenum Press: New York and London1. 1977: p 1.

2. Craven. B. M. Cholestenol Chstal Structure: Adducts and Esters. In The Phusical Chentism of Lipids. Handbook of Lipid Research: Small. D. M., Ed.: Plenum Press: New York, 1986: Vol. 4. pp 149182.

3. Park. Y. J. Bull. Korem Chem. Soc. 2005. 26. 2072

4. Park. Y. J.: Oh. T. H. Korean J. Chstallography 2000. H. 84.

5. Craven. B. M.: DeTitta. G. T. J. Chent. Soc. Perkin $I 1$ 1976. 814

6. Otwinowski. Z.: Minor. W. In Methods in Enzznologn: Carter. Ir.. C. W.: Sweet. R. M.. Eds.: Academic Press: New York. 1997: Vol. 276. part A. pp 307-326.

7. Sheldrick, G. M. SHEL IS and SHEL 1-97; Institute Fur Anorganishe Chemie, Der Universität Göttingen: Germany. 1997.

8. Park. Y. J. Bull. Korean Chent Soc. 2004. 25.751.

9. Park. Y. J. J. Korem Chen. Soc. 2005. 19.334.

10. Park. Y. J.: Bae. T.: Lah. M. S. Acta Cnst. 2005. E61.02312.

11. Park. Y. J. Acta Crust. 2006, E62, 04983.

12. Barrall, E. M. Thermodyamics of Mesophase Transitions in Liquid Coystals: Saeva, F. D.. Ed.: New York, Marcel Dekker Inc.: 1979: pp 335-363. 